\title{
O CLUBE TABAJARA E AS NARRATIVAS DE RACISMO EM ENCRUZILHADA DO SUL: ENTRE TENSÃO E IDENTIDADE ÉTNICA
}

\section{Daiana Hermann ${ }^{1}$}

Este artigo tem por objetivo discutir algumas questões surgidas ao longo de uma pesquisa etnográfica realizada junto a moradores negros do município de Encruzilhada do Sul/RS, que freqüentavam os antigos carnavais do Clube Tabajara. Tal agremiação apresenta como singularidade o fato de ser um espaço constituído por e para a população negra do município, uma vez que na época de sua fundação, em 1949, os negros eram constrangidos a não freqüentar os outros clubes existentes na cidade, bem como participar dos blocos carnavalescos destes.

Encruzilhada do Sul caracteriza-se enquanto um município de grande extensão territorial, de herança sesmeira e histórico de trabalho escravo, de modo que a história da cidade contém em sua dinâmica o enraizamento de famílias negras, de modo geral oriundas do trabalho latifundiário, que se deslocam no processo de consolidação da república, no âmbito urbano, para atividades diversas. $\mathrm{O}$ centro da cidade, que abriga a igreja, a praça, os prédios públicos e privados em estilo português colonial, a rua comercial e os dois clubes freqüentados pela classe média e pelas elites rural e urbana do município, além de casas residenciais que o circundam, são envoltos por bairros quase tão antigos quanto este: o Lava-Pés e o entorno da Quatro de Dezembro². Habitados por grande parte da população negra do município, que se via sem espaço para festejar, dançar, conversar, comemorar datas importantes, esses dois bairros abrigam o início da história do Clube Tabajara, cuja primeira sede foi no Lava-Pés e passou para a Quatro de Dezembro ainda na década de 1950, onde se mantém até hoje.

Tal clube passou a figurar no circuito de umas das festividades mais tradicionais do município: o carnaval. Por volta das décadas de 40, 50, 60 e 70, o carnaval de Encruzilhada se caracterizava pelo desfiles dos clubes da cidade na rua principal e pelos bailes no interior dos destes, momento que era o ápice da festa. Atualmente o modelo carnavalesco segue os padrões do carnaval carioca, com concurso entre escolas de samba. Este modelo, adotado na década de 80, fez com que cada clube da cidade

\footnotetext{
${ }^{1}$ Universidade Federal do Rio Grande do Sul, Brasil.

${ }^{2}$ Oficialmente, Quatro de Dezembro é uma rua, porém é usual que todos que moram, ou nesta rua ou em todas aquelas que se localizam depois desta em direção oposta ao centro da cidade, digam que são "da quatro" ou que moram "pra baixo da quatro". Embora a prefeitura tenha a delimitação e nomenclatura oficiais dos bairros, tal não reflete em nada as formas como a população de muitos bairros encruzilhadenses se refere e delimita os espaços que ocupam.
} 
instituísse sua Escola de Samba ${ }^{3}$. É nesse contexto que surge a Escola de Samba Mocidade Independente, em 1985, fomentada por um grupo de amigos freqüentadores do Clube Tabajara que conceberam a idéia de "mostrar que os negros também podem se organizar e fazer um carnaval bonito", segundo um informante.

Com a priorização do carnaval de rua e do concurso entre escolas de samba, os bailes nos clubes perderam sua centralidade. Além disso, com o advento de leis que criminalizam a discriminação racial ${ }^{4}$, os clubes do Comércio e Encruzilhadense tiveram que abrir suas portas para toda a comunidade encruzilhadense. Tais fatores combinados fizeram com que o Clube Tabajara, hoje, se encontre praticamente fechado, raramente promovendo eventos festivos, mesmo no carnaval, restringindo sua participação no cenário carnavalesco da cidade enquanto espaço de ensaios e muamba da Escola de Samba Mocidade Independente.

Porém, embora esteja quase desativado, o clube se mantém vivo e constantemente atualizado nas lembranças dos velhos carnavalescos que viveram no Tabajara seus "melhores carnavais, os carnavais da juventude". Assim, enquanto constituidor de uma memória da sociabilidade negra de Encruzilhada do Sul, esse clube ainda é um espaço central, podendo ser tomando, nas palavras de Halbwachs (2004b) enquanto um importantíssimo marco social da memória.

Ao focar a construção da memória coletiva acerca dos espaços de sociabilidade constituídos na e pela festa, neste caso o carnaval, tomamos a festa (Del Priore, 1994; Cunha, 2002; Chianca, 2007) enquanto um ritual que permite compreender as estruturas e relações sociais e, ao mesmo tempo, enquanto espaço de sociabilidade (Velho, 2002; 2004) que viabiliza a constituição de "comunidades afetivas" (Halbwachs, 2004a; 2004b), se tornando, assim, um ancoradouro da memória coletiva do grupo. Na presente discussão, a memória social dos narradores negros do Tabajara acerca desse clube e de seus carnavais, reverbera a tensão étnica presente na sua história desde a fundação.

A partir dar narrativas sobre as festas negras em Encruzilhada do Sul compreendemos ser possível reconstruir a experiência temporal desses espaços de sociabilidade através da narrativa, tomando-a, como quer Paul Ricoeur (1994), enquanto uma forma privilegiada de representação do tempo. O tempo, aqui, não é visto enquanto

\footnotetext{
${ }^{3}$ Cada escola de samba pertence a um dos clubes da cidade: Mimi pertence ao Clube do Comércio; Palmeiras ao Clube Encruzilhadense e Mocidade ao Clube Tabajara.

${ }^{4}$ Lei 7.716/1989. Dispõe sobre crimes resultantes de discriminação ou preconceito de raça, cor, etnia, religião ou procedência nacional, classificando-os como crimes inafiançáveis, punível com prisão de até cinco anos e multa.
} 
um transcorrer contínuo, linear, mas sim constituído por uma série de rupturas e diferentes espessuras (Bachelard, 1988:38). Para além do tempo vivido, abordaremos também o tempo pensado que é desprendido da narrativa enquanto uma rítmica, o tempo enquadrado pela razão, contando a experiência dos narradores a partir do "ser no mundo" (Bachelard, 1965).

\section{Os caminhos da pesquisa: porquê clubes negros em Encruzilhada?}

Minha inserção etnográfica inicia ainda no ano de 2007, quando pude assistir pela primeira vez a um carnaval em Encruzilhada do Sul. Vi passar na 'avenida' - a rua central da cidade que é fechada para a ocasião - as três escolas de samba da cidade: Mocidade Independente, Mimi e Palmeiras. Mesmo um olhar superficial revelava as grandes diferenças entre Mocidade e as outras duas escolas: enquanto estas entravam na avenida com carros alegóricos, fantasias e alegorias luxuosas e bem feitas e com um grande contingente de passistas brancas que, como ouvi dizer várias vezes "nem sabem sambar", a Mocidade apresentava um desfile mais "pobre". Sem poder comprar os itens necessários para confeccionar fantasias e adereços mais elaborados, as vestes das passistas eram simples; os carros alegóricos, em menor quantidade, não tinham a riqueza de detalhes e o caprichoso acabamento das demais, nem comportavam tantos passistas. A grande maioria dos sambistas eram negros e negras, com "samba no pé” e o samba-enredo visivelmente contagiava muito mais a audiência do que as outras duas escolas. Cheguei a ouvir de um rapaz que estava ao meu lado na platéia que "os puxadores da Mimi parecem que estão cantando música gauchesca”, em referência ao compasso do samba e tom de voz dos interpretes.

Tais comentários e atitudes por parte das pessoas com quem conversava (sempre negros moradores dos bairros periféricos) explicitavam uma tensão étnica que parecia se potencializar no contexto carnavalesco. Perguntando um pouco mais acerca da história do carnaval encruzilhadense, não demoraram a aparecer narrativas sobre casos de discriminação racial nos clubes do centro da cidade, dizendo que há até alguns anos atrás era proibida a entrada de negros nestes locais ${ }^{5}$. Foi quando ouvi de um informante

\footnotetext{
${ }^{5} \mathrm{Um}$ dos casos mais polêmicos de suposto racismo nos últimos anos em Encruzilhada do Sul aconteceu há cerca de 12 anos, durante as festividades de carnaval de 1998 no Clube do Comércio, que tramitou na Justiça até o final de 2007, quando um acordo entre as partes encerrou o processo. Trata-se do caso de uma então estudante de psicologia, negra, que na época foi barrada no baile de carnaval do Clube do Comércio, sob alegação do porteiro de que "era da tradição do clube" de negros não poderem participar de seus eventos festivos. O acordo ficou estabelecido em um pagamento R \$ 30.800,00 por danos morais à parte ofendida. Comenta-se na cidade, desde o encerramento do processo, que a escola de samba Mimi,
} 
que "foi por causa disso que o Tabajara foi fundado, pra que os negros também tivessem um lugar onde se juntar e fazer festa, já que nos clube dos brancos eles não podiam entrar".

Depois de perceber que existia uma grande rede de pessoas negras que, ao falar do carnaval de encruzilhada, sempre evocavam a lembrança do "antigo Tabajara" e seus "carnavais de antigamente", vi que tal clube abriga uma importante parcela da memória negra da cidade, e que os narradores de tais memórias constroem suas identidades na tensão de ser negro em uma sociedade discriminadora. Tensão essa se torna presente sempre que se fala de um clube que surgiu para acolher os negros da cidade, uma vez que eram proibidos de freqüentar "espaços de brancos".

\section{Seu Guabiju, o Oxalá da Mocidade}

Uma dessas pessoas é seu Guabiju. Negro de cabelos já bem brancos pela idade, seu Guabiju trabalhou durante a sua adolescência em uma fazenda do interior do município. Já adulto migrou para a cidade, onde se casou e teve três filhas, duas das quais são professoras e a terceira é psicóloga. Ainda hoje, mesmo estando aposentado, continua trabalhando, eventualmente, como pedreiro. Mas do que gosta mesmo são das festas da terceira idade, as quais freqüenta sozinho, sem a esposa. A disposição para "fazer festa" sempre esteve presente na vida de seu Guabiju, principalmente na época do carnaval. Ele conta que

quando era moço, trabalhava 'pra fora' ${ }^{6}$ e pra ir no carnaval, quando terminava o serviço, montava no cavalo e ia pra cidade, pular carnaval no clube! Fazia festa até de madrugada e não me importava de ter que trabalhar no outro dia caindo de sono, sem ter dormido nada (risos)... naquele tempo a gente sabia se divertir, dançava, cantava as marchinhas de carnaval e pulava até de manhazinha.

A disposição de seu Guabiju para contar histórias sobre o Tabajara e a Mocidade é enorme. Logo no primeiro dia que nos conhecemos fui à casa dele, levada pelas suas filhas, Magda e Dagmar. Elas diziam que

o pai sempre gostou de festa, faz tudo pra sempre participar... agora mesmo, nessas festas da terceira idade ele não falta uma! E no carnaval, então, ele se presta pra tudo! Teve um ano que ele saiu de Oxalá da Mocidade, em carro alegórico e tudo!

ligada ao Clube do Comércio, tem decaído muito em seus desfiles, o que seria resultado do déficit financeiro advindo do pagamento do acordo para que o processo por racismo fosse encerrado.

6 “Trabalhar pra fora quer dizer trabalhar no campo, em oposição ao trabalho na cidade" 
Vestiram ele de branco e ainda pintaram o cabelo dele de Errorex, pra ficar mais branquinho ainda (risos)

O Oxalá da Mocidade, como dizem as filhas, também guarda na memória uma série de marchinhas de carnaval que eram entoadas nos bailes do Tabajara e que vinham do Rio de Janeiro através dos "rouxinóis" (livrinhos com as letras das marchinhas, as quais todos decoravam). Ao falar das marchinhas, seu Guabiju começou a cantar uma delas, levantando-se para mostrar alguns dos passos coreografados que eram dançados nos baile de carnaval dos clubes, mas já se desculpando, pois não estava "muito inteiro" devido à festa da terceira idade a que havia ido no dia anterior:

\footnotetext{
"Menina vai, com jeito vai,

Porque um dia, a casa cai..

Vou te levar pra tomar banho em Paquetá

Fazer piquenique na Barra da Tijuca

Ou pra fazer um programa no Chuá

Menina vai, com jeito vai,

Porque um dia, a casa cai..."
}

No que tange ao fato de o Tabajara ser um clube "de negros", seu Guabiju conta que os estes "não podiam entrar no Encruzilhadense e no Clube do Comércio, então faziam a sua festa separado, lá no Tabajara", mas que "tinha muitos negros que realmente não se 'ajeitavam', não tinham compostura para freqüentar as festas, viviam fazendo "anarquia". Já quanto a ele, mesmo existindo discriminação aos negros em Encruzilhada, nunca sofrera com isso, pois "sabia se comportar, andava sempre bem vestido, mesmo não tendo dinheiro pra comprar roupas caras, porque o importante é saber se comportar, ter compostura". Seu Guabiju diz que também ensinou isso para as filhas: "disse pra elas que não podiam ficar num canto, se escondendo, que deveriam se enturmar com todo mundo", sempre tendo "compostura e educação", falando com orgulho que conseguiu, com muito esforço, dar uma boa educação e "formar elas na faculdade".

\section{Rosa e Teresinha: o valor de estudar}

Assim como seu Guabiju, as irmãs Teresinha e Rosa também são duas antigas freqüentadoras do Clube Tabajara. Mas sua família tem ainda mais envolvimento com o clube: seu avô e seu tio foram dois dos fundadores do "clube dos negros", cuja sede inicial, no bairro Lava-Pés, ficava próximo à casa em que cresceram e na qual Rosa mora até hoje. As duas irmãs foram assíduas freqüentadoras do Tabajara durante a 
juventude, "nos bons tempo do clube, dos carnavais, das matinês, dos bailes de debutantes". Quando falamos de carnaval, Rosa recorre logo à enorme quantidade de álbuns de fotografia que registram os inúmeros eventos dos quais participou no clube.

Rosa é professora aposentada do ensino fundamental e infantil. Formou-se na cidade vizinha de Santa Cruz do Sul e lecionou nesse município durante alguns anos, antes de ir para Porto Alegre e mais tarde para Santa Catarina, para onde foi acompanhando o primeiro marido. Este, porém, faleceu ainda nos primeiros anos de casamento e Rosa voltou para Encruzilhada, ficou vivendo com a mãe e lecionando nas escolas do município. Hoje casou-se novamente, mas não tem filhos. Gosta de festas e de política, diz que foi uma das fundadoras do PTB no município e há alguns anos filiou-se no PSDB. Já foi candidata à vereadora duas vezes. Com um enorme sorriso acolheu com muito interesse a idéia de conversar sobre o Tabajara. Rosa lamenta que o clube "já não é mais o que era antes", tendo decaído muito com o passar dos anos e o abandono dos antigos organizadores. Para ela, o carnaval também mudou muito com a adoção do modelo de concurso entre as escolas de samba, pois

antigamente a gente ia pra se divertir, pra juntar os amigos... e a coisa foi ficando um luxo, o carnaval, tanto que é só o Mimi que ganha, não tem mais graça... a gente só tem o samba e a batucada, mas condições de concorrer com eles a gente não tem... isso já não tem mais nem graça!

Comento com Rosa que fui buscar nos jornais das décadas de 50, 60 e 70, notícias sobre o carnaval, mas que só havia encontrado referência aos outros dois clubes e pouquíssima coisa sobre o Tabajara. Ao que ela me diz:

\footnotetext{
sabe que isso é tão gozado, parece que eles não anotavam nada! Tu não acha nada escrito sobre o Tabajara, não existe nada! Mais do que eles mostram é o Encruzilhadense e o Comércio mesmo, né?... e os negos também ficam muito omissos, também... eu acho assim que não pode ser tão omisso... tem que pedir pelo espaço deles, eles não lutam, não vão nas coisas! Eu sempre vou, eu e meu marido a gente adora ir nos bailes dos clubes... e muitas vezes é só eu que to lá dentro de nega... as vezes ta eu e mais dois... porque que eu não vou ir? Eu adoro dançar! Eu acho que a gente tem que saber o valor da gente e não se sentir menos que ninguém, não tem porquê! Só por causa da cor? Eu nunca tive problema com a minha cor, adoro a minha cor... mas eu acho que tudo é dentro de casa, eu acho, tudo começa na família... o meu pai era analfabeto mas ele tinha visão de muitas coisas...
}

Ao falar do tempo que cursava ensino superior em Santa Cruz do Sul, Rosa comenta sobre o fato de ter havido poucos negros na universidade e reflete sobre a postura que os negros daquela cidade adotavam em espaços dominados por brancos. 
Para ela, constranger-se e isolar-se por ser negro é motivo de indignação, e localiza na educação dada pelos pais tal forma de pensar:

na minha época nego não estudava em Santa Cruz. Nós era entre 50 e tantos na sala de aula e era só eu de nega, a única nega que tinha era eu! E os negos lá em Santa Cruz, eles mesmo ficam assim... parece que ficam isolados, eles tem medo dos lugar, assim... sabe que quando eu morava lá eu ia nos lugar e dançava e eles ficavam: ah, credo, eu não vou sair pra lugar nenhum! E quando a gente ia eles ficavam: ah, vocês vão, vocês vão!? E eu dizia: claro, a gente vai... a gente não vai de graça, vai pagar pra entrar, né? A minha mãe que sempre dizia: se arrumem, se enfeitem, se convidarem tem que ir! A minha mãe era uma pessoa muito... a minha mãe falava, conversava muito com a gente, sabe... (...) a minha mãe era muito bonita, todo mundo dizia que era a mulata mais bonita que tinha aqui em Encruzilhada quando ela era nova... minha mãe fazia muitos trabalhos manuais assim, ela fazia muita coisa bonita... ela tinha só a quarta série mas ela lia muito! Tu conversava com ela e tu pensava, assim, que ela tinha uma faculdade! Ela sabia de tudo um pouco, ela falava de tudo e fazia tudo que era trabalho manual, ela adorava fazer crochê... tudo que ela olhava ela fazia! E ela fazia toda a nossa roupa, parecia que a gente comprava na loja, tão bem que ela fazia! e ela frequentava o Tabajara. Meu pai e minha mãe eram muito assim... freqüentavam os lugares, gostavam muito de sair, de se enfeitar...

A valorização da educação, de estudar, de freqüentar a escola, também é um tema recorrente nas falas de Rosa e Teresinha, assim como de seu Guabiju e suas filhas, referindo-se ao estudo enquanto uma forma de driblar os embaraços criados pela cor da pele em comunidades discriminadoras. Na fala de Rosa, o pai é referido enquanto paradigma desse valor:

(...) e o meu pai era analfabeto, eu e minha irmã que ensinamos meu pai a escrever o nome dele e contar até cem, pra ele poder tirar as passagens, porque ele era cobrador do ônibus que ia pra Santa Cruz. Mas o meu pai sempre dizia: enquanto eu viver, se vocês estudarem vocês não precisam trabalhar, vocês vão sempre estudar... e a minha mãe conseguiu botar esse espírito em nós de que a gente tem que sempre ler... eu e minha irmã, a gente lê muito.

A irmã de Rosa, Teresinha, tem 64 anos e vive atualmente em São Paulo, onde trabalha como educadora, tradutora e ativista em uma ONG que acolhe refugiados de países em guerra, além de militar também no movimento negro. Teresinha é divorciada e não tem filhos. Diz que dedicou toda sua vida a estudar, viajar e conhecer pessoas, o que, segundo ela, seu trabalho e as diversas atividades em que se envolve sempre lhe proporcionaram. Quando a conheci, em agosto de 2010, estava passando alguns meses na casa da irmã, para descansar e rever as pessoas da terra natal. Mesmo assim reuniu uma turma de jovens de Encruzilhada que precisavam de aulas particulares e lecionava português em alguns dias da semana. Teresinha me disse que no fim de agosto viajaria 
para Porto Alegre, onde permaneceria até janeiro de 2011, uma vez que faz parte de uma comunidade naturalista que se fixou naquela cidade.

Assim como Rosa, Teresinha também freqüentou, quando jovem, o Clube Tabajara e os bailes de carnaval. Logo que expliquei a ela o propósito da minha pesquisa com os antigos freqüentadores do clube, ela conta a seguinte história:

Eu desde nova já trabalho essas questões raciais, então comigo aconteceu um fato quando eu era nova, que nos fechamos um restaurante, onde hoje é o shopping das delícias, ali era o City Bar, e eu tinha uns 16 anos naquela época e eu convidei uma moça de Porto Alegre, também negra, que era namorada do meu irmão, e nós fomos neste restaurante... e já éramos pessoas conhecidas, né... ai nós fomos nesse restaurante, eram novos donos, né, de uma família aqui de Encruzilhada e eles disseram então que a partir daquele momento eles iam atender os negros, os morenos, na parte de trás do restaurante! E ai eu cheguei em casa... não entramos, né, viemos embora, contei pra minha mãe e na hora a minha mãe chamou meu padrinho Sonino, chamo de padrinho porque foi meu padrinho de casamento, Sonino Baroni, que era advogado conhecido e fizemos um mandado de segurança pra fechar... ai veio o Correio do Povo na época, a gente acionou os direitos... na época não tinha esse nome de Direitos Humanos, mas a gente acionou uma equipe de médicos, de advogados negros.. então veio o jornal... é uma história bem interessante! Fechamos! O restaurante nunca mais funcionou com aqueles donos.

Ao contar esse caso, Teresinha reflete acerca do racismo implicado nele e explicita como se posiciona e o que pensa ante os casos de discriminação:

Sartre tem um livro muito interessante sobre o racismo e ele fala ali que o racismo é um problema de quem o tem! E ai, sob essa ótica que ele falava, eu fiquei pensando: o que que ele quis dizer com isso? Porque? Porque ele é um sentimento que incomoda a quem o tem... se uma pessoa não gosta de mim porque eu sou negra, o que que eu posso fazer? Não posso fazer nada! É um problema dele. Ele vai, cada vez que encontrar uma pessoa de cor negra, ou... um japonês, ou um homossexual... qualquer outro grupo social que difere do seu grupo social, é ele que vai ter esse tipo de sentimento, de ojeriza, de repulsão, de ódio... então ele é que tem que trabalhar. (...) A questão racial é uma questão psicológica. É uma questão patológica. O racismo foi uma válvula de escape das pessoas... até quando a pessoa tem um problema, alguma coisa que incomoda, se passa uma pessoa de um grupo social diferente, a pessoa vai agredir aquele como uma forma de válvula de escape, entende? Ela canaliza o ódio, a dor, pro outro.

Ainda pensando sobre o racismo, Teresinha lembra outro fato, que teria sido narrado a elas por sua mãe:

Tem um fato muito interessante que aconteceu, a minha mãe sempre contava esse caso: tinha uma família, minha mãe morava em Dom Marcos e minha avó tinha uma venda lá... e então tinha uma família lá, mas muuuito pobre! Pobre... minha mãe dizia que essas pessoas moravam numa casa de pau a pique, de barro, tanto que tinha muito mal de chagas, né? Então eles iam visitar a minha vó. Minha vó tinha muita fartura e deixava eles comendo, né. E um dia ia ter uma festa e a minha vó disse que ia convidar eles pra vir ajudar na festa, já que eles comiam lá o ano todo... 
mas ai eles disseram que não iam! Que eles eram pobres mas eram branco! (risos) Eles eram pobres, ir lá comer eles podiam, minha avó tinha obrigação de dar comida pra eles... mas agora trabalhar pros negros, não! 'Desculpe dona Euzébia, mas nós semo pobre, mas semo branco!' no fundo no fundo é uma questão de comparação também, né? que pior ainda que ser pobre era ser negro.

Para Teresinha, falar do Clube Tabajara e dos seus freqüentadores é falar da história de conflitos étnicos da cidade. Através da narrativa, ela reflete e significa as diversas sutilezas e cruezas dessa tensão e busca em referências e leituras já feitas, como em Sartre, para compreender e solucionar o problema: "o racismo é um sentimento que incomoda a quem o tem".

\section{Conclusão}

Para Bachelard (1988: 8), aquilo que dura na memória é aquilo que ainda faz sentido no tempo presente e o que remete ao futuro, ao devir. As lembranças de seu Guabiju, Rosa e Teresinha sobre o Tabajara e os carnavais do clube apontam sempre para a constituição de um espaço de sociabilidade negra que tensiona e é tensionado pelas narrativas de preconceito racial e de restrição dos espaços permitidos aos negros em Encruzilhada na segunda metade do século XX.

Em Halbwachs (2004a) a experiência temporal dos indivíduos repousa na sua interação com diferentes grupos, uma vez que são os laços de solidariedade que conformam sua memória social. Neste sentido, a constituição de comunidades afetivas permite acomodar diferentes ritmos e durações à memória e que, no processo da narrativa, dão sentido a experiência individual (Ricoeur, 1991). A interação dos negros encruzilhadenses no Clube Tabajara, dentro de um universo com poucas alternativas de participação em clubes de brancos, acaba moldando um pertencimento e uma memória negra ligada ao local.

Porém, essa "identidade do nós" constituída a partir do espaço de sociabilidade comum e também pela classificação externa que dizia que negros deveriam ocupar espaços aparte dos brancos é tensionada pelas trajetórias pessoais de cada narrador, que interpreta tais questões tendo em vista suas vivências familiares e também em outros círculos, lançando luz sobre diversos consórcios entre as narrativas sobre o clube Tabajara e a discriminação étnica em Encruzilhada do Sul.

Ao se manter à margem dos afetados diretos do racismo na cidade, seu Guabiju não nega que tal tenha ocorrido e que tenha presenciado muitos desses casos. Mas interpreta sua trajetória baseado em valores familiares e posturas pessoais que, segundo 
ele, impediram que sofresse esses constrangimentos pelo fato de ser negro. Para ele, assim como para Rosa, é necessária certa "compostura" e uma postura de inclusão, de não acanhamento diante do diferente que os classifica pela cor da pele. Também é evidente, nas falas de ambos, a menção à educação formal enquanto uma forma privilegiada, senão a única, de incluir-se e mesmo sobressair-se na sociedade discriminadora. Daí, logo aparecem referências à família: da parte de Rosa e Teresinha aos pais, tomados como exemplos de como se portar e educar os filhos; de seu Guabiju, a referência à família é através das filhas, as quais ele conseguiu "dar estudo".

Já quanto a Teresinha, sua fala mostra alguns elementos interpretativos alcançados a partir de sua vasta socialização "no mundo", fora da cidade natal, onde convive com pessoas das mais diversas culturas e profissões e tem acesso a leituras que buscam compreender o fenômeno do racismo. Em contrapartida à vivência "no mundo", seu interesse e preocupação com esse tema refletem a sua vivência "em casa", a partir das tensões étnicas da cidade natal.

Nesses termos, podemos apontar o clube Tabajara e os seus bailes de carnaval, enquanto tempo e espaço de sociabilidade privilegiados para interpretar as vivências, consórcios e tensões da comunidade negra de Encruzilhada do Sul desde a sua fundação até o seu declínio, por volta da década de 80, uma vez que tais vivências ainda ecoam e duram na memória dos antigos carnavalescos e frequentadores desse clube e orientam suas interpretações de mundo até hoje.

\section{Referências}

BACHELARD, Gastón. A dialética da duração. São Paulo: Ática, 1988.

BACHELARD, Gastón. L'intuition de l'instant. Paris: Denoel, 1965.

BOSI, Ecléa. Memória e sociedade. Lembranças de velhos. São Paulo: Queiroz Ed. Ltda. e EDUSP, 1987.

CUNHA, Maria Clementina Pereira (Org.). Carnavais e outras $f(r)$ estas. Ensaios de história social da cultura. Campinas, São Paulo: Editora da Unicamp, Cecult, 2002.

CHIANCA, Luciana de Oliveira. "Quando o campo está na cidade: migração, identidade e festa". In: Sociedade e Cultura, v. 10, n. 1. Goiânia: UFG, 2007. p.45-59.

DEL PRIORE, Mary. Festas e utopias no Brasil Colonial. São Paulo: Brasiliense, 1994. ECKERT, Cornelia e ROCHA, Ana Luiza Carvalho. O tempo e a cidade. Porto Alegre: Ed. UFRGS, 2005.

HALBWACHS, Maurice. A memória coletiva. São Paulo: Centauro, 2004a.

HALBWACHS, Maurice. Los marcos sociales de la memoria. Barcelona: Anthropos, 2004b.

RICOEUR, Paul. Tempo e narrativa. Campinas: Papirus, 1994. 
RICOEUR, Paul. "O si e a identidade narrativa". $O$ si-mesmo como um outro. Campinas: Papirus, 1991.

VELHO, Gilberto. Antropologia das sociedades complexas. Rio de Janeiro: Jorge Zahar, 1994.

VELHO, Gilberto. Subjetividade e sociedade: uma experiência de geração. Rio de Janeiro: Zahar, 2002.

Recebido em: 23/12/2010

Aprovado em: 30/03/2011 